\title{
The immune response to influenza in older humans: beyond immune senescence
}

\author{
Janet E. McElhaney ${ }^{1 *}$, Chris P. Verschoor ${ }^{1}$, Melissa K. Andrew² ${ }^{2}$ Laura Haynes ${ }^{3}$, George A. Kuchel ${ }^{3}$ and \\ Graham Pawelec ${ }^{1,4}$
}

\begin{abstract}
Despite widespread influenza vaccination programs, influenza remains a major cause of morbidity and mortality in older adults. Age-related changes in multiple aspects of the adaptive immune response to influenza have been well-documented including a decline in antibody responses to influenza vaccination and changes in the cellmediated response associated with immune senescence. This review will focus on T cell responses to influenza and influenza vaccination in older adults, and how increasing frailty or coexistence of multiple $(\geq 2)$ chronic conditions contributes to the loss of vaccine effectiveness for the prevention of hospitalization. Further, dysregulation of the production of pro- and anti-inflammatory mediators contributes to a decline in the generation of an effective CD8 T cell response needed to clear influenza virus from the lungs. Current influenza vaccines provide only a weak stimulus to this arm of the adaptive immune response and rely on re-stimulation of CD8 T cell memory related to prior exposure to influenza virus. Efforts to improve vaccine effectiveness in older adults will be fruitless until CD8 responses take center stage.
\end{abstract}

Keywords: Influenza, Influenza vaccination, Hemagglutination inhibition antibody response, Broadly neutralizing antibodies, CD4 and CD8 T cell response, Cytokines, Granzyme B, Dendritic cells, Vaccine adjuvants

\section{Background}

Despite widespread influenza vaccination programs and $>60 \%$ vaccination rates in the population age 65 years and older in many countries, influenza remains a serious threat to the health of older people. In the US, the over 65 population accounts for two-thirds of the 200,000 influenza-related hospitalizations independent of whether they are at high or low risk for serious complications of influenza [1], and older people make up $90 \%$ of the 36,000 deaths each year $[2,3]$. Further, the length of hospital stay for older adults is almost 3-fold higher than 50-64 year olds and 6-fold higher than younger adults [1]. Recent global estimates of seasonal influenza-associated respiratory deaths have shown

\footnotetext{
* Correspondence: jmcelhaney@hsnri.ca

'Health Sciences North Research Institute, 41 Ramsey Lake Road, Sudbury, ON P3E 5J1, Canada

Full list of author information is available at the end of the article
}

mortality rates of $50-100$ per 100,000 in the over 75 population; non-respiratory causes of influenzaassociated mortality require further investigation [4]. The aim of this article is to highlight those ageassociated changes in the immune response to influenza vaccination that are due to multiple chronic conditions, their associated inflammatory effects, and increasing frailty. These changes go beyond what can be explained by immune senescence and are associated with the increased risk for serious complications of influenza including catastrophic disability. Our search of the existing literature in the preparation of this article included the terms: influenza, influenza vaccination, multiple chronic conditions or multi-morbidity, frailty, inflammation, disability, and humoral and cell-mediated immune responses. Current research efforts will require a deeper understanding of how the health of the 'usual' older person affects the cell-mediated immune response and how 
adjuvants may play a role in enhancing cellular immune mechanisms in the development of more effective influenza vaccines for older adults.

\section{Burden of influenza}

Older adults are particularly susceptible to severe outcomes of influenza. This is especially true during seasons when $\mathrm{A} / \mathrm{H} 3 \mathrm{~N} 2$ is the predominant circulating strain where dramatic increases in hospitalization rates occur in the population age 65 and older [5, 6]. Cardiovascular events are the most common extra-pulmonary complications of influenza (i.e., myocardial infarction, congestive heart failure, and strokes) with long-term consequences including cardiovascular disease and cognitive decline [7-9]. Dysregulated immune responses associated with multiple chronic conditions result from the chronically elevated levels of circulating inflammatory cytokines, often characterized as 'inflammaging' [10], and could very well be the mechanistic link to these complications of influenza. Specifically, the six leading causes of catastrophic disability including strokes [11, 12], congestive heart failure [13, 14], pneumonia and influenza [15-25], ischemic heart disease [8, 11, 26, 27], cancer and hip fracture $[28,29]$, have all been linked to influenza illness. Furthermore, $15 \%$ of older adults admitted with laboratory-confirmed influenza will experience catastrophic disability with a loss of independence in more than two basic self-care activities [30] and older adults are also vulnerable to diminished quality of life due to loss of independence following hospitalization with influenza [25]. In fact, influenza accounts for nearly $30 \%$ of all disability-adjusted life years lost to infectious disease [31], and influenza hospitalization is estimated to cost more than 2 billion dollars in Canada over the next decade [32]. Older adults, especially those living with chronic conditions and/or frailty, are highly susceptible to severe outcomes of influenza; however, the correlates of protection in this vulnerable population are not well investigated.

\section{Limitations of current influenza vaccines}

Despite recent advances in the development of highdose, adjuvanted, and subunit vaccines, there remain significant challenges to the development of more effective influenza vaccines for older adults, particularly for preventing the most serious complications. Influenza vaccines are annually formulated to stimulate strain-specific neutralizing antibody responses to the predicted circulating strains of influenza. These changes in the circulating strains are the result of antigenic drift wherein new strains emerge with human transmission due to the high mutation rates of the influenza A virus and the selection of strains with epitopes on the hemagglutinin (HA) head that are resistant to antibody binding. Vaccine strain mismatch may also result from the loss of glycosylation sites on the HA head in the process of adaptation of the vaccine strains for optimal growth in eggs. These neutralizing antibodies are stimulated in the response to influenza vaccination and thus prevent infection by binding to the HA head and neutralizing the virus to prevent virus entry into the host cell, so-called "sterilizing immunity". Vaccine strain mismatch leads to a loss of strain-specific antibody binding to the critical protective epitopes surrounding the receptor-binding domain of the globular head of hemagglutinin. The hemagglutination inhibition (HAI) assay is the standard measure of strain-specific antibody titers and the rise in HAI antibody titers with vaccination is usually used to estimate vaccine efficacy in clinical trials. Much of the decline in vaccine efficacy with aging has been attributed to "immune senescence", wherein the decline in the antibody response to influenza vaccination is attributed to age-related changes in $\mathrm{B}$ cell and $\mathrm{T}$ cell development and function (reviewed in [33-35]). These studies typically enroll healthy older adults who would be considered non-frail. Similarly, the older adult population represented in large Phase 3 clinical trials is generally healthier than those at an elevated risk and these trials are statistically powered to measure protection against mild to moderate influenza disease not requiring hospital admission. In this case, the antibody response to influenza vaccination may indeed be a good correlate of protection but may not predict "clinical protection" against severe influenza illness and hospitalization in the general population of older adults. A recent study of adults undergoing elective hip replacement has also shown the importance of the bone marrow environment in maintaining memory and effector cells and how the accumulation of both highly differentiated and terminally differentiated CD8 $\mathrm{T}$ cells is associated with declining serum antibody titers against diphtheria. This appears to be related to increased numbers of terminally differentiated CD8 $\mathrm{T}$ cells which negatively affect the maintenance of B cells and plasma cells, while increases in highly differentiated CD8 T cells lead to heightened proinflammatory cytokine levels and potentially toxic effects on B cell maintenance [36].

\section{Impact of frailty on outcomes of influenza}

Frailty is a geriatric syndrome which is multifactorial in etiology, involves complex and dynamic interactions with the elements of biopsychosocial health, and reflects the loss of the adaptive capacity to respond to acute health challenges [37-39]. It has been generally recognized to be age-associated and common in older adults. The frailty phenotype (e.g. the Fried Frailty Score) provides a ternary (three category) view of frailty that considers weakness, slowness, inactivity, exhaustion and 
weight loss, and is associated with adverse outcomes including risk of mortality [40]. In contrast, the Frailty Index is a broader conceptualization [41], which relates to the accumulation of deficits across multiple domains of health and functional status [42], and is a more sensitive measure of the degree of frailty and strongly predicts mortality risk [43] and adverse outcomes [44]. For comparison, standard cutoffs for the frailty index are FI $0-0.1=$ non-frail $; \quad>0.1-0.21=$ pre-frail $; \quad>0.21-0.45=$ frail; $>0.45=$ most frail, and in community-based samples approximately $24 \%$ of older adults are frail [45].

Influenza illness is associated with increases in frailty, measured using a 40-item Frailty Index, among hospitalized older adults. Importantly, frailty is also an important confounder of vaccine effectiveness, and vaccine effectiveness declines with increasing frailty [46]. Our hospital-based influenza surveillance studies using a 40item Frailty Index (FI) in adults age 65 years and older have found that older adult inpatients with laboratoryconfirmed influenza have an average FI of 0.2 [30] indicating that this is a frail population [46] at high risk for catastrophic disability as a consequence of influenza illness. Further, recent studies suggest that the disabling outcomes of influenza [30] are not limited to the over 65 population. In the setting of critical illness, $50 \%$ of patients with pre-existing frailty are under age 65 [47]. Most of these patients are in the 50-64 year-old age range suggesting that multiple chronic conditions are a significant contributor to pre-existing frailty. More importantly, disability and mortality outcomes were dependent on the level of frailty as assessed by the Clinical Frailty Scale [48] and independent of chronological age. The 'response' to influenza vaccination can be measured as a serologic or cell-mediated immune responses but the impact of frailty on these responses has yet to be studied in a manner that captures its dynamic nature reflecting loss of resilience [49-51]. In addition, a protective response to vaccination may differ depending on the outcome studied; protection from mild to moderate illness may be very different from the response needed to prevent severe illness and the pulmonary and extrapulmonary complications of influenza.

In our community studies of the response to influenza vaccination in older adults, using the same 40-item Frailty Index, older adults on average have a Frailty Index of 0.1 (Non-frail are <0.1) (unpublished observations). A systematic review of high-dose relative to standard-dose influenza vaccine trials, showed that the better antibody responses to high-dose influenza vaccine was independent of sex, age $>75$ years old, frailty, and chronic conditions [52]. This is supported by individual studies from Singapore [53], Germany [49], and the U.S. [54], all of which reported that frailty did not have a significant effect on antibody titres following standard dose vaccination in adults 60 and over. Another study originating from the U.S. found the opposite, where antibody responses were significantly impaired in adults that were frail [55]. In apparent contrast, in our randomized trial of high-dose vs. standard-dose vaccine, increasing frailty increased absolute titres post-vaccination as well as the likelihood of being a vaccine responder (i.e., a four-fold rise in HAI antibody titers) [56]. This was similarly observed by Moehling and colleagues, specifically in adults between 50 and 65 years old [51]. A systematic review of MF-59 adjuvanted vs. unadjuvanted influenza vaccine also showed an enhanced antibody response with the adjuvanted formulation in older adults but an analysis of the effects of sex, older age, frailty or chronic conditions was not performed [57]. The disagreement within the literature is perplexing, and at the moment, the underlying reasons are not clear. One possibility is that the relationship between vaccine antibody responses and frailty (if one does indeed exist) depends on the manner in which frailty is measured and also the manner in which changes to antibody titres are classified as indicating responder status. Thus, the studies referred to above, including our own, generally use either the Frailty Phenotype [40] or Frailty Index [42] approach, and treat the measure as either a categorical or continuous manner. Another possibility is that the frailty relationship depends on the vaccine formulation, both the dose and strains targeted. Findings from our clinical trial, which included more than 600 participants, suggest that all of these factors play an important role and should be considered more closely in future studies. Further, these factors may be associated with a loss of reliability of the antibody response to influenza vaccination as a measure of vaccine efficacy and correlate of protection in more frail individuals.

Test-negative case control design studies are another way to investigate the effect of frailty on laboratoryconfirmed influenza-related hospitalizations, an outcome of vaccination that cannot be captured in sufficient numbers in clinical trials to demonstrate the enhanced benefit of newer vaccines. All patients admitted with an acute respiratory illness are included in these studies where those patients with laboratory-confirmed influenza are compared to those patients who are testnegative for influenza [58]. These studies provide annual estimates of influenza vaccine effectiveness for the prevention of hospitalization in Canada through the Serious Outcomes Surveillance (SOS) Network of the Canadian Immunization Research Network [46, 59-61]. More recently, a test-negative case control design incorporating the 40-item Frailty Index in SOS Network studies has demonstrated the importance of considering the level of frailty as a major contributor to the decline in influenza vaccine effectiveness in older adults [46]. This is 
supported by work of Petrie and colleagues [62], which showed that vaccine efficiency in frail older adults is $17 \%$, as compared to $48 \%$ for all adults over 65 years old. These results also suggest that frailty is a major contributor to the risk for serious complications of influenza, even in vaccinated older adults. Understanding the determinants of $\mathrm{T}$-cell mediated clinical protection against serious influenza illness, as a paradigm shift in in the scientific community and US Food and Drug Administration approval pathways remains a major challenge [63].

\section{Cell-mediated immune protection against influenza}

When antibodies fail to protect against influenza infection by providing sterilizing immunity, "clinical protection" relies on cell-mediated immune mechanisms to the clear the virus from infected host cells and prevent the pulmonary and extrapulmonary complications of influenza. Previous studies have shown that heterosubtypic immunity (i.e., cross-protective across multiple influenza A strains) induced in the mucosal tissue of the respiratory tract by influenza infection is mediated by $\mathrm{CD} 8$ cytotoxic $\mathrm{T}$ lymphocyte (CTL) responses [64] and by broadly non-neutralizing antibodies (bNA) through antibody-dependent phagocytosis by alveolar macrophages [65]. Influenza infection stimulates both naïve and memory B cells and CD4 and CD8 T cells (reviewed in [66]), and is required to establish influenza-specific CD8 $\mathrm{T}$ cell immunologic memory. In contrast, current standard seasonal influenza vaccination (inactivated virus) primarily stimulates $\mathrm{B}$ cells and $\mathrm{CD} 4 \mathrm{~T}$ cells, while the CD8 $\mathrm{T}$ cell response relies on re-stimulation of immunologic memory from prior exposure to the virus inactivated influenza vaccines provide only a weak stimulus to virus-specific CD8 T cells. In young adults with low HAI titers, the CTL response to influenza infection has been shown to correlate with protection against influenza illness [67]. More recently, increased levels of interferon (IFN) $\gamma$-producing CD4 $\mathrm{T}$ helper type 1 (Th1)) and CD8 CTL cells responding to the conserved internal proteins of influenza virus, matrix (M1) and nucleoprotein (NP), have been shown to correlate with protection against influenza A strains [68, 69]. Importantly, these internal proteins are shared across the $\mathrm{A} / \mathrm{H} 3 \mathrm{~N} 2$ and $\mathrm{A} / \mathrm{H} 1 \mathrm{~N} 1$ subtypes of influenza $\mathrm{A}$, thus providing heterosubtypic immunity whereby the response to these internal proteins provides protection across multiple strains of influenza. We have shown in multiple studies that the $\mathrm{T}$ cell response following influenza vaccination with split-virus vaccine (SVV) formulations using ex vivo influenza challenge of peripheral blood mononuclear cells (PBMC) correlates with protection in older adults [70-72]. In contrast, a randomized clinical trial of four subunit vaccines (containing no internal proteins) demonstrated an enhanced HAI antibody response to the M59-adjuvanted formulation over the unadjuvanted vaccines [73], but there was no difference in the $\mathrm{T}$-cell response across the four vaccines [74]. Although antibody-dependent phagocytosis as a correlate of protection against influenza illness in humans has not been studied, observations from studies of macrophage function in the context of aging suggest these investigations may be warranted.

\section{Role of innate immune cells in influenza infection}

Comparisons of young and old mice have yielded conflicting results, possibly arising from discrepancies in experimental design, macrophage type studied, and exactly how "old" is defined [75], but at least two studies have shown that peritoneal phagocytic function is impaired with age [76]. Similarly, many studies have revealed ageassociated differences in macrophage functionality in humans (reviewed in [77]). We are unaware of any studies that have investigated changes in human macrophage phagocytic function with age, but a relatively recent study did find that the uptake of opsonized bacteria was significantly reduced in CD14+ monocytes from older adults [78]. This becomes important as influenza infection has been shown to induce inflammation causing lung injury and life-threatening pneumonia, either primary viral pneumonia or secondary bacterial infection [79]. This acute inflammation in response to influenza infection is mediated by lung monocytes and monocytederived dendritic cells that are involved in the detection and clearance of influenza virus and influenza pathogenesis in the lungs [80]. These innate immune cells are not only susceptible to influenza-induced apoptotic and necrotic cell death [81], influenza infection has a direct effect on monocytes which results in the downregulation of Th17-mediated immunity necessary for protection against secondary pneumococcal pneumonia [82]. This effect of influenza infection on the monocyte function necessary for the clearance of pneumococcus has recently been demonstrated in a human challenge model [83].

Natural killer (NK) cells have also been shown in mouse models to contribute to the control of influenza during the early stage of infection through granulemediated (granzyme B and perforin) killing of virusinfected cells [84-87], but can also be killed themselves by the influenza virus. Aged mice show a decline in the numbers and function of NK cells with more immature and less fully mature NK cells. These age-related changes may impair the ability of NK cells to contribute to a strong antiviral response during the early phase of influenza infection [88]. In humans, fatal influenza cases show low numbers of NK cells in the lungs $[89,90]$ and this has been associated with the effects of influenza 
infection in NK cells which inhibits the cytolytic function and cytokine and chemokine secretion [91]. However, there is limited knowledge as to how these age-related changes found in mouse models or in fatal cases of human influenza in young adults relate to outcomes of influenza in older adults [92].

\section{Toll-like receptor agonists as influenza vaccine adjuvants}

Appropriate selection of TLR agonists which stimulate dendritic cells (DC) is needed to improve the CD8 T cell response to influenza challenge in older adults. The primary targets for TLR agonists are the TLR on myeloid $(\mathrm{mDC})$ and plasmacytoid (pDC) dendritic cells but studies have shown that the age-related decline in the engagement of TLR1/2, TLR2/6, TLR3, TLR5, and TLR8 in mDCs and TLR7 and TLR9 in pDCs, may be mediated by dysregulated cytokine production [93]. These results are consistent with our unpublished experiments in which we screened different TLR agonists and found that glucopyranosyl lipid adjuvant formulated in a stable emulsion (GLA-SE, a TLR4 agonist) provided a superior stimulus in terms of cytokine production and that the cytokine response (IL-6, TNF, IL-12) was mainly in $\mathrm{mDC}$ [94]. More recent global analyses using commercially-available TLR agonists such as lipopolysaccharide (LPS) to stimulate TLR4 have also demonstrated age-related changes in innate immune responses after stimulation with different TLR agonists [95]. Using frozen PBMC in these experiments, it was concluded that the delay in the response to TLR agonists in older adults is not due to differences in numbers of DC and monocytes but rather is due to an impairment of downstream signalling events in monocytes and DC. Our studies have shown that functional $\mathrm{mDC}$ do not survive freezing very well and that immune cells may be stripped of important receptors after cryopreservation, both of which could have contributed to the above findings using frozen PBMC. In a comparative systems analysis of the molecular signatures of clinically-tested, non-TLR vaccine adjuvants, GLA-SE was shown to provide better stimulation of different $B$ and $T$ cell subsets [96]. Both components of the GLA/SE adjuvant were found to be required to achieve optimal responses in both arms of the adaptive immune response: specifically, SE for neutralizing antibodies and GLA for induction of $\mathrm{T}$ cell responses [97].

Vaccine adjuvants including TLR agonists have been used to enhance Th and CTL responses to influenza vaccination. Different vaccine adjuvants can stimulate Th1 (e.g. MF59 [squalene based] + CpG [TLR9 agonist]) vs. Th2 (e.g. MF59 alone) responses to influenza vaccination according to the relative degree of Th1 production of IFNY vs. Th2 production of IL-5; these actions contribute to antibody and cell-mediated protection against influenza [98]. However, mice that received MF59 + CpG adjuvanted influenza vaccine were better protected against influenza illness with less weight loss and better survival compared to mice that received MF59adjuvanted vaccine. In addition, these mice showed better resistance to a subsequent bacterial superinfection. It remains to be determined whether vaccine-induced $\mathrm{T}$ helper cells contributed to viral clearance via secretion of immune-activating cytokines and/or via direct effector functions. In aged mice, we have shown that the addition of inflammatory cytokines (IL-1, IL-6 and TNF or IL-2 plus IL- 6 can reverse age-related defects in Th1 cytokine production, proliferation and function [99]. In contrast, human PBMC cultured with influenza vaccine and inflammatory cytokines (IL-1, IL-6 and TNF) showed a suppressed $\mathrm{T}$ cell response to a subsequent influenza challenge [94]. However, the addition of IL-2 and IL-6 to influenza $\mathrm{H} 3 \mathrm{~N} 2$-challenged PBMC cultures restored the proliferative response and function of influenzaspecific CD8 CTL in aged mice and humans to that of their young counterparts [100]. Importantly, our studies have shown that the CTL response to ex vivo influenza challenge is dependent on the presence of $\mathrm{CD} 4 \mathrm{~T}$ cells in the PBMC cultures [100, 101].

\section{T cell correlates of protection}

To the best of our knowledge, we have published the only prospective studies of $\mathrm{T}$ cell correlates of protection against influenza in vaccinated older adults. In multiple studies, we have shown in PBMC that the ratio of IFNy to interleukin (IL)-10 (IFNy:IL10) in supernatants of stimulated PBMC and biological activity of the cytolytic mediator, granzyme B $(\mathrm{GrB})$, in lysates of ex vivo influenza challenged PBMC correlate with protection against influenza illness $[70,71]$ and disease severity in older adults [72]. This GrB activity at 4-weeks postvaccination as a correlate of protection can be demonstrated even among frail older adults [102]. Importantly, we have shown that stimulation of immunologic memory during an influenza infection can subsequently be restimulated by influenza vaccination and these flu+ cases show an enhanced response to vaccination compared to non-infected older adults [71]. These results suggest that the decline in the CTL response to influenza vaccination with aging is a limitation of current vaccines NOT a compromised immune system per se.

\section{The role of influenza internal proteins and adjuvants in new vaccine development}

Novel strategies for stimulating CD8 CTL responses have long been a priority for new vaccine development to provide heterosubtypic immunity across serologically distinct strains of virus [64, 94, 103-105]. Since the current inactivated influenza vaccine formulations 
provide only a weak stimulus to CD8 T cell responses, adjuvanted formulations that enhance $\mathrm{T}$ cell help and antigen presentation to $\mathrm{CD} 8 \mathrm{~T}$ cells are being pursued. Because the response to influenza M1 and NP, correlates with protection in both CD4 [68] and CD8 T cells [69], these internal proteins will be a necessary component of new vaccines for older adults. These internal proteins are absent in influenza subunit vaccines ( $\mathrm{HA}+/-$ neuraminidase), so alternative mechanisms including antibody-mediated protection [106] may explain the enhanced protection of adjuvanted [57] and recombinant HA [107] formulations in older adults. A large randomized clinical trial of an AS03-adjuvanted influenza vaccine in older adults also showed enhanced protection against the influenza $\mathrm{A} / \mathrm{H} 3 \mathrm{~N} 2$ vaccine strain compared to the unadjuvanted formulation [108], and this enhanced protection was comparable to that found in the randomized trial of high-dose influenza vaccine [109].

The importance of including influenza internal viral proteins such as M1 and NP in vaccines has been highlighted in experiments in the mouse model showing that sequential immunization with whole-inactivated influenza vaccine (containing influenza internal proteins), but NOT a subunit vaccine (no internal proteins), could alleviate the severity of infection with antigenically drifted viruses from the vaccine strains and potentially improve protection to unpredictable seasonal infection [110]. Importantly, depletion of $\mathrm{T}$ cells prior to challenge revealed that CD8 $\mathrm{T}$ cells, but not CD4 $\mathrm{T}$ cells, contributed to cross-protection. However, CD4 T cells are needed to provide cytokine-mediated 'help' to optimize the generation of a CD8 T cell response. Similarly, human PBMC stimulated with different inactivated influenza vaccines showed statistically significant differences in the numbers of activated IFNy-producing cells depending on the amount of internal proteins contained in the vaccine [111]. These results are consistent with a clinical study showing that vaccine effectiveness for the prevention of hospitalization in older adults was $77.8 \%$ in recipients of SVV (containing M1 and NP) but only $44.2 \%$ in subunit vaccine (surface glycoproteins only) recipients, giving a difference in vaccine effectiveness of 33.5\% [112]. A randomized study of four subunit vaccines (which did not contain M1 and NP) confirmed that while an MF59 adjuvant could stimulate higher antibody responses compared to unadjuvanted influenza vaccines [73], we showed that there was no difference in $\mathrm{T}$ cell responses to adjuvanted vs. nonadjuvanted subunit formulations [74]. Taken together, these results suggest that M1 and NP will need to be included in vaccine formulations designed to prevent the serious complications of influenza in older adults, particularly those who are frail.

Importantly, we have shown in in vitro experiments that there was an increase in the IFN $\gamma: \mathrm{IL}-10$ ratio and
GrB activity in response to influenza challenge when the TLR4 agonist GLA-SE was combined with SVV. This response appears to be mediated by a 10 -fold reduction in IL-10 levels when older adult PBMC are stimulated with GLA-SE plus SVV compared to SVV alone prior to influenza challenge [94]. Our unpublished results show that SVV stimulates IL-2 production and GLA-SE stimulates IL-6 production in these PBMC cultures. Furthermore, we have shown that the combined effects of IL-2 and IL-6 as a supplement in ex vivo influenzachallenged PBMC restores the $\mathrm{CD} 8 \mathrm{~T}$ cell response to that seen in younger adults; the problem is that older adults have a lower frequency of CD8 T cells at baseline [100]. These results suggest a mechanism that can be targeted using vaccine adjuvants to develop more effective influenza vaccines for older adults.

\section{Conclusions}

Current research efforts to support the development of new influenza vaccines have largely focused on hemagglutination inhibition antibody responses. Defining those changes that occur with immune senescence requires studies of relatively healthy older adults who are not generally representative of the over 65 population with multiple chronic conditions, particularly those age 75 years and older. While antibody responses to influenza vaccination may predict protection against influenza infection in community-dwelling older adults, it does not explain the significant increases in their hospitalization rates that occur during influenza seasons where $\mathrm{A} / \mathrm{H} 3 \mathrm{~N} 2$ (relative to $\mathrm{A} / \mathrm{H} 1 \mathrm{~N} 1$ and $\mathrm{B}$ strains) is the predominant circulating strain. Immunologic priming with the first exposure to influenza in childhood (i.e. A/ $\mathrm{H} 1 \mathrm{~N} 1$ for the current older adult cohort) may explain the low hospitalization and death rates during A/H1N1 years, with only the most frail being susceptible to the serious complications of influenza. Further, dysregulated immune responses characterized as 'inflammaging' in the context of multiple chronic conditions and frailty appear to be the mechanistic link to these complications, and go beyond those changes in lymphocyte development and function attributed to immunosenescence. More studies are needed in older adults with multiple chronic conditions to determine how varying levels of frailty lead to the loss of adaptive capacity or resilience and are reflected in multiple measures of the interaction of innate and adaptive immune function. Current influenza vaccines are poor stimulators of the heterosubtypic cell-mediated immunity needed to prevent the serious complications of influenza. We propose that there is a requirement to translate new insights into how cellmediated immune responses to influenza A/H3N2 strains can be enhanced in the design of new influenza vaccines. To address this unmet need, we must first 
understand the interaction between circulating proteins associated with inflammatory processes, the phenotype and function of different immune cells subsets responding to influenza challenge, and prove that cell-mediated immune correlates of protection are valid in older adults. It will also be necessary to better understand how broadly-neutralizing antibodies contribute to heterosubtypic immunity. Finally, our in vitro system using older adult PBMC to simulate the effect of different vaccine/ adjuvants on the response to influenza challenge using our established correlates of protection, and our choice of adjuvants currently in clinical development, serves as a model for pre-clinical testing and an accelerated pathway through the clinical development pipeline.

\section{Abbreviations}

bNA: Broadly non-neutralizing antibodies; CTL: Cytotoxic T Iymphocytes; DC: Dendritic cells; myeloid (mDC) and plasmacytoid (pDC); GrB: Granzyme B; HAl: Hemagglutination inhibition; IFN: Interferon; IL: Interleukin; M1: Influenza matrix protein; NP: Influenza nucleoprotein; PBMC: Peripheral blood mononuclear cells; SOS: Serious Outcomes Surveillance Network; SW: Splitvirus influenza vaccines; Th1: T helper type 1; Th2: T helper type 2; TLR: Tolllike receptor; TNF: Tumour-necrosis factor

\section{Acknowledgements}

None.

\section{Authors' contributions}

All authors contributed to the research under NIH R01AG048023 and the studies involving GLA-SE (NIH U01AI074449. The corresponding author (JEM) wrote the initial draft and all authors contributed comments to each draft. All authors finalized the document for submission of the manuscript. The author(s) read and approved the final manuscript.

\section{Funding}

Our randomized trial of high-dose vs. standard dose influenza vaccine was supported by NIH R01AG048023.

\section{Availability of data and materials}

Not applicable.

\section{Ethics approval and consent to participate}

Not applicable.

\section{Consent for publication}

All authors have consented to the publication of this manuscript.

\section{Competing interests}

JEM's institution has received honoraria for presentations and participation in advisory boards and data safety and monitoring boards and related travel reimbursements from Sanofi, GSK, Pfizer and Merck outside of the submitted work. CPV has no competing interests. MKA has received grant funding from GSK, Sanofi and Pfizer and honoraria from Sanofi and the Canadian Frailty Network. LH and GAK declare no competing interest. GP has received honoraria and research support from Immatics Biotechnologies, Celgene, Pfizer, Sanofi, 4D-Pharma, Clasado and The Croeni Foundation, and consults for Repair Biotechnologies, Inc.

\section{Author details}

${ }^{1}$ Health Sciences North Research Institute, 41 Ramsey Lake Road, Sudbury, ON P3E 5J1, Canada. ${ }^{2}$ Department of Medicine and Canadian Centre for Vaccinology, Dalhousie University, Halifax, NS, Canada. ${ }^{3}$ University of Connecticut Center on Aging, UConn Health Center, Farmington, CT, USA. ${ }^{4}$ Department of Immunology, University of Tübingen, Tübingen, Germany.
Received: 4 January 2020 Accepted: 13 April 2020

Published online: 07 May 2020

\section{References}

1. Molinari NA, Ortega-Sanchez IR, Messonnier ML, Thompson WW, Wortley $P M$, Weintraub $E$, et al. The annual impact of seasonal influenza in the US: measuring disease burden and costs. Vaccine. 2007;25(27):5086-96.

2. Thompson WW, Shay DK, Weintraub E, Brammer L, Cox N, Anderson LJ, et al. Mortality associated with influenza and respiratory syncytial virus in the United States. JAMA. 2003;289(2):179-86.

3. Thompson WW, Shay DK, Weintraub E, Brammer L, Bridges CB, Cox NJ, et al. Influenza-associated hospitalizations in the United States. JAMA. 2004; 292(11):1333-40.

4. Iuliano AD, Roguski KM, Chang HH, Muscatello DJ, Palekar R, Tempia S, et al. Estimates of global seasonal influenza-associated respiratory mortality: a modelling study. Lancet. 2018;391(10127):1285-300.

5. Centers for Disease Control Weekly U.S. Influenza Surveillance Report (FluView) [Internet]. 2017 [cited 01/14/2018]. Available from: https://www. cdc.gov/flu/weekly/pastreports.html.

6. Control CfD. Flu Surv-net 2018 [cited 2018 January 6, 2018]. Available from: https://www.cdc.gov/flu/weekly/weeklyarchives2017-2018/EIPrates49.html.

7. Corrales-Medina VF, Alvarez KN, Weissfeld LA, Angus DC, Chirinos JA, Chang CC, et al. Association between hospitalization for pneumonia and subsequent risk of cardiovascular disease. Jama. 2015:313(3):264-74.

8. Kwong JC, Schwartz KL, Campitelli MA, Chung H, Crowcroft NS, Karnauchow $T$, et al. Acute myocardial infarction after laboratory-confirmed influenza infection. N Engl J Med. 2018;378(4):345-53.

9. Tate JA, Snitz BE, Alvarez KA, Nahin RL, Weissfeld LA, Lopez O, et al. Infection hospitalization increases risk of dementia in the elderly. Crit Care Med. 2014;42(5):1037-46.

10. Franceschi C, Campisi J. Chronic inflammation (inflammaging) and its potential contribution to age-associated diseases. J Gerontol A Biol Sci Med Sci. 2014:69(Suppl 1):S4-9.

11. Smeeth L, Thomas SL, Hall AJ, Hubbard R, Farrington P, Vallance P. Risk of myocardial infarction and stroke after acute infection or vaccination. $N$ Engl J Med. 2004;351(25):2611-8.

12. Toschke AM, Heuschmann PU, Wood O, Wolfe CD. Temporal relationship between influenza infections and subsequent first-ever stroke incidence. Age Ageing. 2009;38(1):100-3.

13. Vardeny $\mathrm{O}$, Solomon SD. Influenza and heart failure: a catchy comorbid combination. JACC Heart Fail. 2019;7(2):118-20.

14. Panhwar MS, Kalra A, Gupta T, Kolte D, Khera S, Bhatt DL, et al. Effect of influenza on outcomes in patients with heart failure. JACC Heart Fail. 2019; 7(2):112-7.

15. Collins JP, Campbell AP, Openo K, Farley MM, Cummings CN, Hill M, et al. Outcomes of immunocompromised adults hospitalized with laboratoryconfirmed influenza in the United States, 2011-2015. Clin Infect Dis; 2019. [Epub ahead of print].

16. Hak E, Wei F, Nordin J, Mullooly J, Poblete S, Nichol KL. Development and validation of a clinical prediction rule for hospitalization due to pneumonia or influenza or death during influenza epidemics among communitydwelling elderly persons. J Infect Dis. 2004;189(3):450-8.

17. Walker TA, Waite B, Thompson MG, McArthur C, Wong C, Baker MG, et al. Risk of severe influenza among adults with chronic medical conditions. J Infect Dis. 2020:221(2):183-90.

18. Metersky ML, Masterton RG, Lode H, File TM Jr, Babinchak T. Epidemiology, microbiology, and treatment considerations for bacterial pneumonia complicating influenza. Int J Infect Dis. 2012;16(5):e321-31.

19. Rello J, Pop-Vicas A. Clinical review: primary influenza viral pneumonia. Crit Care. 2009;13(6):235

20. Deng JC. Viral-bacterial interactions-therapeutic implications. Influenza Other Respir Viruses. 2013;7(Suppl 3):24-35.

21. Seki M, Kosai K, Yanagihara K, Higashiyama Y, Kurihara S, Izumikawa K, et al. Disease severity in patients with simultaneous influenza and bacterial pneumonia. Intern Med. 2007:46(13):953-8.

22. Ballinger MN, Standiford TJ. Postinfluenza bacterial pneumonia: host defenses gone awry. J Interf Cytokine Res. 2010;30(9):643-52.

23. Shrestha S, Foxman B, Weinberger DM, Steiner C, Viboud C, Rohani P. Identifying the interaction between influenza and pneumococcal pneumonia using incidence data. Sci Transl Med. 2013;5(191):191ra84 
24. Campigotto A, Mubareka S. Influenza-associated bacterial pneumonia; managing and controlling infection on two fronts. Expert Rev Anti-Infect Ther. 2015;13(1):55-68.

25. Falsey AR, Hennessey PA, Formica MA, Cox C, Walsh EE. Respiratory syncytial virus infection in elderly and high-risk adults. N Engl J Med. 2005;352(17): 1749-59.

26. Cardoso R, Rivera M, Czarny MJ, Knijnik L, Fernandes A, Blumenthal RS, et al. In-Hospital Management and Outcomes of Patients With Acute Myocardial Infarction and Influenza. Am J Cardiol. 2020;125(6):840-4.

27. Barnes M, Heywood AE, Mahimbo A, Rahman B, Newall AT, Macintyre CR. Acute myocardial infarction and influenza: a meta-analysis of case-control studies. Heart. 2015;101(21):1738-47.

28. Ferrucci L, Guralnik JM, Pahor M, Corti MC, Havlik RJ. Hospital diagnoses, Medicare charges, and nursing home admissions in the year when older persons become severely disabled. Jama. 1997:277(9):728-34.

29. Fraenkel M, Yitshak-Sade M, Beacher L, Carmeli M, Mandelboim M, Siris E, et al. Is the association between hip fractures and seasonality modified by influenza vaccination? An ecological study. Osteoporos Int. 2017;28(9):26117.

30. Andrew MK, MacDonald S, Ye L, Ambrose A, Boivin G, Diaz-Mitoma F, et al. Impact of frailty on influenza vaccine effectiveness and clinical outcomes: Experience from the Canadian Immunization Research Network (CIRN) Serious Outcomes Surveillance (SOS) Network 2011/12 Season. Ottawa: Canadian Immunization Conference; 2016

31. Cassini A, Colzani E, Pini A, Mangen MJ, Plass D, McDonald SA, et al. Impact of infectious diseases on population health using incidence-based disabilityadjusted life years (DALYs): results from the Burden of Communicable Diseases in Europe study, European Union and European Economic Area countries, 2009 to 2013. Euro Surveill. 2018;23(16).

32. Ng C, Ye L, Noorduyn SG, Hux M, Thommes E, Goeree R, et al. Resource utilization and cost of influenza requiring hospitalization in Canadian adults: a study from the serious outcomes surveillance network of the Canadian immunization research network. Influenza Other Respir Viruses. 2018;12(2): 232-40.

33. Nikolich-Zugich J. The twilight of immunity: emerging concepts in aging of the immune system. Nat Immunol. 2018:19(1):10-9.

34. Goronzy JJ, Weyand CM. Mechanisms underlying T cell ageing. Nat Rev Immunol. 2019;19(9):573-83.

35. Dugan HL, Henry C, Wilson PC. Aging and influenza vaccine-induced immunity. Cell Immunol. 2020;348:103998.

36. Naismith E, Pangrazzi L, Grasse M, Keller M, Miggitsch C, Weinberger B, et al. Peripheral antibody concentrations are associated with highly differentiated $T$ cells and inflammatory processes in the human bone marrow. Immun Ageing. 2019;16(1):21.

37. Bergman H, Ferrucci L, Guralnik J, Hogan DB, Hummel S, Karunananthan S, et al. Frailty: an emerging research and clinical paradigm--issues and controversies. J Gerontol A Biol Sci Med Sci. 2007:62(7):731-7.

38. Strandberg TE, Pitkala KH. Frailty in elderly people. Lancet. 2007;369(9570): 1328-9.

39. Inouye SK, Studenski S, Tinetti ME, Kuchel GA. Geriatric syndromes: clinical, research, and policy implications of a core geriatric concept. J Am Geriatr Soc. 2007;55(5):780-91

40. Fried LP. Ferrucci $L$, Darer J, Williamson JD, Anderson G. Untangling the concepts of disability, frailty, and comorbidity: implications for improved targeting and care. J Gerontol A Biol Sci Med Sci. 2004;59(3):255-63.

41. Stretton CM, Latham NK, Carter KN, Lee AC, Anderson CS. Determinants of physical health in frail older people: the importance of self-efficacy. Clin Rehabil. 2006;20(4):357-66.

42. Rockwood K, Rockwood MR, Mitnitski A. Physiological redundancy in older adults in relation to the change with age in the slope of a frailty index. Am Geriatr Soc. 2010;58(2):318-23.

43. Song X, Mitnitski A, Rockwood K. Prevalence and 10-year outcomes of frailty in older adults in relation to deficit accumulation. J Am Geriatr Soc. 2010; 58(4):681-7.

44. Clegg A, Young J, lliffe S, Rikkert MO, Rockwood K. Frailty in elderly people. Lancet. 2013;381(9868):752-62.

45. Hoover M, Rotermann M, Sanmartin C, Bernier J. Validation of an index to estimate the prevalence of frailty among community-dwelling seniors. Health Rep. 2013;24(9):10-7.

46. Andrew MK, Shinde V, Ye L, Hatchette T, Haguinet F, Dos Santos G, et al. The importance of frailty in the assessment of trivalent inactivated influenza vaccine effectiveness against influenza-related hospitalization in elderly people. J Infect Dis. 2017;216(4):405-14.

47. Brummel NE, Bell SP, Girard TD, Pandharipande PP, Jackson JC, Morandi A, et al. Frailty and subsequent disability and mortality among patients with critical illness. Am J Respir Crit Care Med. 2017;196(1):64-72.

48. Rockwood K, Song X, MacKnight C, Bergman H, Hogan DB, McDowell I, et al. A global clinical measure of fitness and frailty in elderly people. Cmaj. 2005;173(5):489-95.

49. Bauer JM, De Castro A, Bosco N, Romagny C, Diekmann R, Benyacoub J, et al. Influenza vaccine response in community-dwelling German prefrail and frail individuals. Immun Ageing. 2017;14:17.

50. Zhang HT, McGrath LJ, Wyss R, Ellis AR, Sturmer T. Controlling confounding by frailty when estimating influenza vaccine effectiveness using predictors of dependency in activities of daily living. Pharmacoepidemiol Drug Saf. 2017:26(12):1500-6.

51. Moehling KK, Nowalk MP, Lin CJ, Bertolet M, Ross TM, Carter CE, et al. The effect of frailty on $\mathrm{HAl}$ response to influenza vaccine among communitydwelling adults $>/=50$ years of age. Hum Vaccin Immunother. 2018;14(2): 361-7.

52. Samson SI, Leventhal PS, Salamand C, Meng Y, Seet BT, Landolfi V, et al. Immunogenicity of high-dose trivalent inactivated influenza vaccine: a systematic review and meta-analysis. Expert Rev Vaccines. 2019;18(3):295-308.

53. Narang V, Lu Y, Tan C, Camous XFN, Nyunt SZ, Carre C, et al. Influenza vaccine-induced antibody responses are not impaired by frailty in the community-dwelling elderly with natural influenza exposure. Front Immunol. 2018:9:2465.

54. Van Epps P, Tumpey T, Pearce MB, Golding H, Higgins P, Hornick T, et al. Preexisting immunity, not frailty phenotype, predicts influenza postvaccination titers among older veterans. Clin Vaccine Immunol. 2017; 24(3):e00498-16.

55. Yao X, Hamilton RG, Weng NP, Xue QL, Bream JH, Li H, et al. Frailty is associated with impairment of vaccine-induced antibody response and increase in post-vaccination influenza infection in community-dwelling older adults. Vaccine. 2011:29(31):5015-21.

56. Loeb N, Andrew MK, Loeb M, Kuchel GA, Haynes L, McElhaney JE, et al. Frailty is associated with increased hemagglutinin-inhibition titres in a 4year randomized trial comparing standard and high dose influenza vaccination. Open Forum Infect Dis; 2020. In Press.

57. Nicolay U, Heijnen E, Nacci P, Patriarca PA, Leav B. Immunogenicity of allV3, MF59-adjuvanted seasonal trivalent influenza vaccine, in older adults $>/=65$ years of age: meta-analysis of cumulative clinical experience. Int J Infect Dis. 2019;85S:S1-9.

58. McElhaney JE, Andrew MK, McNeil SA. Estimating influenza vaccine effectiveness: evolution of methods to better understand effects of confounding in older adults. Vaccine. 2017:35(46):6269-74.

59. McNeil SA, Andrew MK, Ye L, Haguinet F, Hatchette TF, ElSherif M, et al. Interim estimates of 2014/15 influenza vaccine effectiveness in preventing laboratory-confirmed influenza-related hospitalisation from the serious outcomes surveillance network of the Canadian immunization research network, January 2015. Euro Surveill. 2015;20(5):21024.

60. Nichols MK, Andrew MK, Hatchette TF, Ambrose A, Boivin G, Bowie W, et al. Influenza vaccine effectiveness to prevent influenza-related hospitalizations and serious outcomes in Canadian adults over the 2011/12 through 2013/ 14 influenza seasons: a pooled analysis from the Canadian immunization research network (CIRN) serious outcomes surveillance (SOS network). Vaccine. 2018:36(16):2166-75.

61. Mulpuru S, Li L, Ye L, Hatchette T, Andrew MK, Ambrose A, et al. Effectiveness of influenza vaccination on hospitalizations and risk factors for severe outcomes in hospitalized patients with COPD. Chest. 2019;155(1):69-78.

62. Petrie JG, Ohmit SE, Cheng CK, Martin ET, Malosh RE, Lauring AS, et al. Influenza vaccine effectiveness against Antigenically drifted influenza higher than expected in hospitalized adults: 2014-2015. Clin Infect Dis. 2016:63(8): 1017-25.

63. Effros RB. Role of T lymphocyte replicative senescence in vaccine efficacy. Vaccine. 2007;25(4):599-604.

64. Nguyen HH, Moldoveanu Z, Novak MJ, van Ginkel FW, Ban E, Kiyono H, et al. Heterosubtypic immunity to lethal influenza a virus infection is associated with virus-specific CD8(+) cytotoxic T lymphocyte responses induced in mucosa-associated tissues. Virology. 1999;254(1):50-60.

65. He F, Madhan S, Kwang J. Baculovirus vector as a delivery vehicle for influenza vaccines. Expert Rev Vaccines. 2009;8(4):455-67. 
66. Grant EJ, Josephs TM, Loh L, Clemens EB, Sant S, Bharadwaj M, et al. Broad CD8(+) T cell cross-recognition of distinct influenza a strains in humans. Nat Commun. 2018:9(1):5427.

67. McMichael AJ, Gotch FM, Noble GR, Beare PA. Cytotoxic T-cell immunity to influenza. N Engl J Med. 1983;309(1):13-7.

68. Wilkinson TM, Li CK, Chui CS, Huang AK, Perkins M, Liebner JC, et al. Preexisting influenza-specific CD4+ T cells correlate with disease protection against influenza challenge in humans. Nat Med. 2012;18(2):274-80.

69. Sridhar S, Begom S, Bermingham A, Hoschler K, Adamson W, Carman W, et al. Cellular immune correlates of protection against symptomatic pandemic influenza. Nat Med. 2013;19(10):1305-12.

70. McElhaney JE, Xie D, Hager WD, Barry MB, Wang Y, Kleppinger A, et al. T cell responses are better correlates of vaccine protection in the elderly. $J$ Immunol. 2006;176(10):6333-9.

71. McElhaney JE, Ewen C, Zhou X, Kane KP, Xie D, Hager WD, et al. Granzyme B: correlates with protection and enhanced CTL response to influenza vaccination in older adults. Vaccine. 2009:27:2418-25.

72. Shahid Z, Kleppinger A, Gentleman B, Falsey AR, McElhaney JE. Clinical and immunologic predictors of influenza illness among vaccinated older adults. Vaccine. 2010;28(38):6145-51.

73. Scheifele DW, McNeil SA, Ward BJ, Dionne M, Cooper C, Coleman B, et al. Safety, immunogenicity, and tolerability of three influenza vaccines in older adults: results of a randomized, controlled comparison. Hum Vaccin Immunother. 2013:9(11):2460-73.

74. Kumar A, McElhaney JE, Walrond L, Cyr TD, Merani S, Kollmann TR, et al. Cellular immune responses of older adults to four influenza vaccines: results of a randomized, controlled comparison. Hum Vaccin Immunother. 2017; 13(9):2048-57.

75. Linehan E, Fitzgerald DC. Ageing and the immune system: focus on macrophages. Eur J Microbiol Immunol (Bp). 2015;5(1):14-24.

76. Albright JM, Dunn RC, Shults JA, Boe DM, Afshar M, Kovacs EJ. Advanced age alters monocyte and macrophage responses. Antioxid Redox Signal. 2016;25(15):805-15.

77. Plowden J, Renshaw-Hoelscher M, Engleman C, Katz J, Sambhara S. Innate immunity in aging: impact on macrophage function. Aging Cell. 2004;3(4): 161-7.

78. Hearps AC, Martin GE, Angelovich TA, Cheng WJ, Maisa A, Landay AL, et al. Aging is associated with chronic innate immune activation and dysregulation of monocyte phenotype and function. Aging Cell. 2012;11(5): 867-75.

79. Halstead ES, Umstead TM, Davies ML, Kawasawa YI, Silveyra P, Howyrlak J, et al. GM-CSF overexpression after influenza a virus infection prevents mortality and moderates M1-like airway monocyte/macrophage polarization. Respir Res. 2018;19(1):3.

80. Duan M, Hibbs ML, Chen W. The contributions of lung macrophage and monocyte heterogeneity to influenza pathogenesis. Immunol Cell Biol. 2017:95(3):225-35.

81. Atkin-Smith GK, Duan M, Chen W, Poon IKH. The induction and consequences of influenza a virus-induced cell death. Cell Death Dis. 2018; 9(10):1002.

82. Loughran ST, Power PA, Maguire PT, McQuaid SL, Buchanan PJ, Jonsdottir I, et al. Influenza infection directly alters innate IL-23 and IL-12p70 and subsequent IL-17A and IFN- $\gamma$ responses to pneumococcus in vitro in human monocytes. PLoS One. 2018;13(9):e0203521.

83. Jochems SP, Marcon F, Carniel BF, Holloway M, Mitsi E, Smith E, et al. Inflammation induced by influenza virus impairs human innate immune control of pneumococcus. Nat Immunol.

2018;19(12):1299-308.

84. Ge MQ, Ho AW, Tang Y, Wong KH, Chua BY, Gasser S, et al. NK cells regulate CD8+ T cell priming and dendritic cell migration during influenza a infection by IFN-gamma and perforin-dependent mechanisms. J Immunol. 2012;189(5):2099-109.

85. He XS, Draghi M, Mahmood K, Holmes TH, Kemble GW, Dekker CL, et al. T cell-dependent production of IFN-gamma by NK cells in response to influenza a virus. J Clin Invest. 2004;114(12):1812-9.

86. Hwang I, Scott JM, Kakarla T, Duriancik DM, Choi S, Cho C, et al. Activation mechanisms of natural killer cells during influenza virus infection. PLoS One. 2012;7(12):e51858.

87. Verbist KC, Rose DL, Cole CJ, Field MB, Klonowski KD. IL-15 participates in the respiratory innate immune response to influenza virus infection. PLoS One. 2012;7(5):e37539.
88. Beli E, Clinthorne JF, Duriancik DM, Hwang I, Kim S, Gardner EM. Natural killer cell function is altered during the primary response of aged mice to influenza infection. Mech Ageing Dev. 2011;132(10):503-10.

89. Denney L, Aitken C, Li CK, Wilson-Davies E, Kok WL, Clelland C, et al. Reduction of natural killer but not effector CD8 T lymphocytes in three consecutive cases of severe/lethal H1N1/09 influenza a virus infection. PLoS One. 2010;5(5):e10675.

90. Welliver TP, Garofalo RP, Hosakote Y, Hintz KH, Avendano L, Sanchez K, et al. Severe human lower respiratory tract illness caused by respiratory syncytial virus and influenza virus is characterized by the absence of pulmonary cytotoxic lymphocyte responses. J Infect Dis. 2007;195(8):1126-36.

91. Mao H, Tu W, Liu Y, Qin G, Zheng J, Chan PL, et al. Inhibition of human natural killer cell activity by influenza virions and hemagglutinin. J Virol. 2010;84(9):4148-57.

92. Pulendran B, Maddur MS. Innate immune sensing and response to influenza. Curr Top Microbiol Immunol. 2015;386:23-71.

93. Panda A, Qian F, Mohanty S, van Duin D, Newman FK, Zhang L, et al. Ageassociated decrease in TLR function in primary human dendritic cells predicts influenza vaccine response. J Immunol. 2010;184(5):2518-27.

94. Behzad H, Huckriede A, Haynes L, Gentleman B, Coyle K, Wilschut JC, et al. GLA-SE, a synthetic TLR4 agonist, enhances T cell responses to influenza vaccine in older adults. J Infect Dis. 2012;205(3):466-73.

95. Metcalf TU, Cubas RA, Ghneim K, Cartwright MJ, Grevenynghe JV, Richner $J M$, et al. Global analyses revealed age-related alterations in innate immune responses after stimulation of pathogen recognition receptors. Aging Cell. 2015;14(3):421-32

96. Olafsdottir TA, Lindqvist M, Nookaew I, Andersen P, Maertzdorf J, Persson J, et al. Comparative systems analyses reveal molecular signatures of clinically tested vaccine adjuvants. Sci Rep. 2016;6:39097.

97. Heeke DS, Lin R, Rao E, Woo JC, McCarthy MP, Marshall JD. Identification of GLA/SE as an effective adjuvant for the induction of robust humoral and cell-mediated immune responses to EBV-gp350 in mice and rabbits. Vaccine. 2016;34(23):2562-9.

98. Zurli V, Gallotta M, Taccone M, Chiarot E, Brazzoli M, Corrente F, et al. Positive contribution of adjuvanted influenza vaccines to the resolution of bacterial superinfections. J Infect Dis. 2016;213(12):1876-85.

99. Haynes L, Eaton SM, Burns EM, Rincon M, Swain SL. Inflammatory cytokines overcome age-related defects in CD4 T cell responses in vivo. J Immunol. 2004;172(9):5194-9.

100. Zhou X, Hopkins JW, Wang C, Brahmakshatriya V, Swain SL, Kuchel GA, et al. IL-2 and IL-6 cooperate to enhance the generation of influenza-specific CD8 T cells responding to live influenza virus in aged mice and humans. Oncotarget. 2016;7(26):39171.

101. Zhou X, McElhaney JE. Age-related changes in memory and effector T cells responding to influenza a/H3N2 and pandemic a/H1N1 strains in humans. Vaccine. 2011;29(11):2169-77.

102. McElhaney JE, Gravenstein S, Upshaw CM, Hooton JW, Krause P, Drinka P, et al. Granzyme B: a marker of risk for influenza in institutionalized older adults. Vaccine. 2001:19(27):3744-51.

103. Ray SJ, Franki SN, Pierce RH, Dimitrova S, Koteliansky V, Sprague AG, et al. The collagen binding alpha1 beta1 integrin VLA-1 regulates CD8 T cellmediated immune protection against heterologous influenza infection. Immunity. 2004;20(2):167-79.

104. Liang S, Mozdzanowska K, Palladino G, Gerhard W. Heterosubtypic immunity to influenza type a virus in mice. Effector mechanisms and their longevity. J Immunol. 1994;152(4):1653-61.

105. Budimir N, de Haan A, Meijerhof T, Waijer S, Boon L, Gostick E, et al. Critical role of TLR7 signaling in the priming of cross-protective cytotoxic $T$ lymphocyte responses by a whole inactivated influenza virus vaccine. PLoS One. 2013;8(5):e63163.

106. Cowling BJ, Perera R, Valkenburg SA, Leung NHL, luliano AD, Tam YH, et al. Comparative Immunogenicity of Several Enhanced Influenza Vaccine Options for Older Adults: A Randomized, Controlled Trial. Clin Infect Dis; 2019. [Epub ahead of print].

107. Dunkle LM, Izikson R, Patriarca P, Goldenthal KL, Muse D, Callahan J, et al. Efficacy of recombinant influenza vaccine in adults 50 years of age or older. N Engl J Med. 2017;376(25):2427-36.

108. McElhaney JE, Beran J, Devaster JM, Esen M, Launay O, Leroux-Roels G, et al. AS03-adjuvanted versus non-adjuvanted inactivated trivalent influenza vaccine against seasonal influenza in elderly people: a phase 3 randomised trial. Lancet Infect Dis. 2013;13(6):485-96. 
109. DiazGranados CA, Dunning AJ, Kimmel M, Kirby D, Treanor J, Collins A, et al. Efficacy of high-dose versus standard-dose influenza vaccine in older adults. N Engl J Med. 2014;371(7):635-45.

110. Dong W, Bhide Y, Sicca F, Meijerhof T, Guilfoyle K, Engelhardt OG, et al. Cross-protective immune responses induced by sequential influenza virus infection and by sequential vaccination with inactivated influenza vaccines. Front Immunol. 2018;9:2312.

111. Co MD, Orphin L, Cruz J, Pazoles P, Green KM, Potts J, et al. In vitro evidence that commercial influenza vaccines are not similar in their ability to activate human T cell responses. Vaccine. 2009;27(2):319-27.

112. Talbot HK, Nian H, Zhu Y, Chen Q, Williams JV, Griffin MR. Clinical effectiveness of split-virion versus subunit trivalent influenza vaccines in older adults. Clin Infect Dis. 2015;60(8):1170-5.

\section{Publisher's Note}

Springer Nature remains neutral with regard to jurisdictional claims in published maps and institutional affiliations.

Ready to submit your research? Choose BMC and benefit from:

- fast, convenient online submission

- thorough peer review by experienced researchers in your field

- rapid publication on acceptance

- support for research data, including large and complex data types

- gold Open Access which fosters wider collaboration and increased citations

- maximum visibility for your research: over $100 \mathrm{M}$ website views per year

At BMC, research is always in progress.

Learn more biomedcentral.com/submissions 